\title{
A Phenomenological Study to Explore the Challenges in Mental Health Nursing Practice towards Developing Practice Guidelines
}

\author{
Nivamani Barman
}

BSc. Nursing Officer, LGBRIMH, Tezpur, Assam

\begin{abstract}
Background: Nurses were facing various challenges while providing care to patients with mental illness. The study aims to explore those challenges so that practice guidelines can be developed.

Methodology: Approach- Qualitative, Research Design- Phenomenological study, Sample- Nursing personnel, Sample size- 10, Sampling technique- Purposive sampling technique, Setting- Indoor of Tertiary Care Hospital, Inclusion Criteria- Both male and female, Nurses working in Indoor and with work experience of at least one year.

Results: Results shows that $10 \%$ of the subjects are male, $90 \%$ were female, $70 \%$ were Hindu, $30 \%$ were Christian, $10 \%$ were GNM, $20 \%$ were BSc. Nurse, $60 \%$ were DPN, $10 \%$ were Post Basic BSc. nurses, $70 \%$ were married, $30 \%$ unmarried, $40 \%$ of the subjects had 1-3 years of work experience, $60 \%$ had more than 10 years of work experience and no one had exposed to any training programs associated with it. Thematic analysis shows that major challenges were more work load, less number of staff, lack of personal safety and security, restricted hospital facility, psychopathology of acutely ill patients, negative attitude of family members and limited continuing up gradation of knowledge.

Conclusion: The study results show that, nurses faced various challenges while delivering care to patients with mental illness.
\end{abstract}

Key Words: Challenges, Mental Health Nursing Practice, practice guideline

\section{INTRODUCTION}

Challenge means to face a situation that needs great mental and physical attempt in order to be done successfully. Mental Health Nursing Practice is a challenging job. It is due to the various factors like misconceptions about the mental illness, lack of knowledge and awareness, limited mental health personnel, poor social support and very less number of research studies to explore the challenges. Therefore the study will reveal the challenges faced by Mental Health Nurses while rendering care for the mentally ill patients admitted in the Tertiary Care Hospital.

The research studies in this area are very less in number especially in India. So it is an important area for research to explore the challenges so that effective practice guidelines can be formed for better care. An ethnographic investigation was conducted by Michelle Cleary, Central Sydney Area Mental Health Service (CSAMHS), New South Wales, Australia; which was concerned with the way mental health nurses' construct their practice in an acute inpatient psychiatric unit in light of the current challenges, demands and influences brought about by service reforms of the 1990s. The setting for this study was a 22beded acute inpatient mental health facility. Over a 5-month period, data were collected through field work observations, focused interviews and discussion groups. In this article, common cultural practices in relation to the imperatives of relationships, power, restrictions and safety are discussed. The findings demonstrate how the client 
stabilization role of the unit locates these imperatives as central to the delivery of nursing care. The discussion reveals nurses negotiating relationships that are contradictory and challenging in ordinary and everyday ways within the exigencies of daily practice.

\section{RESEARCH METHODOLOGY}

$>$ Research approach:

Research approach is qualitative in nature.

$>$ Research design:

Phenomenological study.

Sample:
Sample of the study contains the nurses working in the indoor of Tertiary care hospital.

Sample size:

The sample size is 10

$>$ Sampling technique:

Sampling technique used is purposive sampling technique.

Setting of the study:

The setting of the study is Indoor of Tertiary Care Hospital, Tezpur at Assam.

\section{ANALYSIS OF DATA:}

Data were analyzed by thematic evaluation and content evaluation.

Table 1: Socio demographic characteristics of the nurses

\begin{tabular}{|c|c|c|c|c|}
\hline SI. No & Variable & Category & Frequency & Percentage \\
\hline \multirow[t]{2}{*}{1} & \multirow[t]{2}{*}{ Gender } & Male & 1 & 10 \\
\hline & & Female & 9 & 90 \\
\hline \multirow[t]{2}{*}{2} & \multirow[t]{2}{*}{ Religion } & Hindu & 7 & 70 \\
\hline & & Christian & 3 & 30 \\
\hline \multirow[t]{4}{*}{3} & \multirow[t]{4}{*}{ Education } & GNM & 1 & 10 \\
\hline & & Bsc nursing & 2 & 20 \\
\hline & & Dpn & 6 & 60 \\
\hline & & Post basic Bsc NSG & 1 & 10 \\
\hline \multirow[t]{2}{*}{4} & \multirow[t]{2}{*}{ Marital status } & Married & 7 & 70 \\
\hline & & Unmarried & 3 & 30 \\
\hline \multirow[t]{2}{*}{5} & \multirow[t]{2}{*}{ Working experience } & $1-3$ years & 4 & 40 \\
\hline & & More than 10 years & 6 & 60 \\
\hline 6. & Exposure to CNE programme related to challenges & Nil & & \\
\hline \multicolumn{3}{|c|}{ 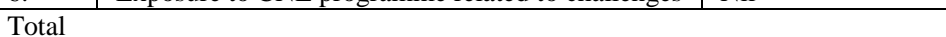 } & 10 & 100 \\
\hline
\end{tabular}

MAJOR CHALLENGES ARE...

$>$ More work load

$>$ Less number of staff

$>$ Psychopathology of acutely ill patient

$>$ Lack of personal safety and security

$>$ Restricted hospital facility

$>$ Negative attitude of family members

$>$ Limited continuing up gradation of knowledge

\section{SUBTHEMES ARE...}

\section{More work load}

- Increased mental stress

- Critical thinking/reviewing of literature is not possible

- Continues alertness and observation

- Unable to prevent relapse

\section{Less number of staff}

- Providing standard care

- Difficult documentation
- Constant monitoring of patients

3. Psychopathology of acutely ill patient

- Lack of insight

- Suicidal

- Violent

- Absconding tendency

- Unable to maintain patient right

4. Lack of personal safety and security

- Verbal abuse

- Physical abuse

\section{Restricted Hospital facility}

- Limited safety measures

6. Negative attitude of family members

- Lack of knowledge

- Lack of family support 


\section{Limited knowledge up gradation \\ - Medication \\ - Standard care protocol \\ - Management of acute emergency}

\section{DISCUSSION}

Finding of the qualitative study reveals that lack of care personnel, more work load, restricted facility in psychiatric hospital and limited continuing knowledge up gradation are major challenges in providing care to mentally ill. A study by Eren $\mathrm{N}$ in Turkey reveals that insufficient personnel, excessive workload, lack of in service training, working condition were leading cause for unethical behavior of the psychiatric nurses.

Lack of personal safety and security, negative attitude of the family members are also major challenges found in the presented study. Nancy P. Hanrahan and Linda $\mathrm{H}$. Aiken in a study found that quality of patient care by the nurses is lower in psychiatric specialty than in Medical Surgical specialty. Psychiatric nurses also experienced more verbal abuse, physical injuries and complaints from patients and families.

\section{CONCLUSION}

Nurses in Mental Health Nursing practice face lots of challenges while caring patients. It is very important to find out the challenges they used to face and some guidelines so that the challenges can be overcome. According to the results, it is clear that nurses have to face the major challenges in their everyday work to provide quality care. Research studies related to this field were very less. Therefore more studies welcome so that hidden problems can find out and can be managed well to improve the quality nursing care.

\section{ACKNOWLEDGEMENT}

I hereby acknowledged Dr.
Arunjyoti Baruah, HOD, Dept. of Psychiatric Nursing, LGBRIMH, Tezpur, for her constant guidance and motivation.

\section{Conflict of Interest: None}

\section{Source of Funding: None}

\section{Ethical Approval: Approved}

\section{REFERENCES}

1. Brar KN, Rawat HC. Textbook of Advanced Nursing Practice. New Delhi: Jaypee Brothers Medical Publishers (p) ltd, 2015

2. Basavanthappa BT. Fundamentals of Nursing. $2^{\text {nd }}$ ed. New Delhi: Jaypee Brothers Medical Publishers (p) ltd; 2009

3. Potter AP, Perry GA. Fundamentals of Nursing. $7^{\text {th }}$ ed. New Delhi: Elsevier, a division of Elsevier India (p) ltd; 2009

4. Sharma KS. Nursing Research \& Statistics. New Delhi: Elsevier, a division of Elsevier India (p) ltd; 2011

5. Nursing ethics [internet]; [cited 2015 Sept2]. Available from htpp:/www.googlebook.com

6. Eren N. Nurses' attitudes toward ethical issues in psychiatric inpatient settings. Nurs Ethics. 2014 May;21(3):359-73. doi: 10.1177/0969733013500161.

7. Johnstone J, Costa DC, Turale S. Registered and enrolled nurses' experience of ethics and human rights issues in nursing practice. Australian Journal of Advanced Nursing vol 22[internet]. 2004 [cited Nov 10]; Available from: www.ajan.com.au>vol22.1-4.pdf.

8. Wynn R. Staff's attitudes to the use of restraint and seclusion in a Norwegian university psychiatric hospital. Nord J Psychiatry. 2003;57(6):453-9. doi: $10.1080 / 08039480310003470$.

How to cite this article: Barman N. A phenomenological study to explore the challenges in mental health nursing practice towards developing practice guidelines. Int $J$ Health Sci Res. 2021; 11(4): 210-212. DOI: https://doi.org/10.52403/ijhsr.20210427 